\title{
Efeito do composto orgânico e compactação do solo no milho e nutrientes do solo
}

\author{
Pedro N. F. Rodrigues ${ }^{1}$, Mário M. Rolim ${ }^{2}$, Egidio Bezerra Neto², Raimundo N. T. Costa ${ }^{3}$, \\ Elvira M. R. Pedrosa $\&$ Veronildo S. O liveira ${ }^{2}$
}

\begin{abstract}
RESU MO
Quando bem aproveitados, os resíduos orgânicos conduzem a grandes benefícios disponibilizando matéria orgânica e nutriente ao solo. N este contexto, objetivou-se, no presente estudo, verificar o efeito da aplicação de doses de composto orgânico em dois solos submetidos a diferentes compactações na biomassa seca do milho. Para isto se aplicaram, em 54 vasos, três doses de composto orgânico nas quantidades 0 (testemunha), 40 e $80 \mathrm{~g} \mathrm{dm}^{-3}$, em um Argissolo Vermelho Escuro e em um outro Argissolo

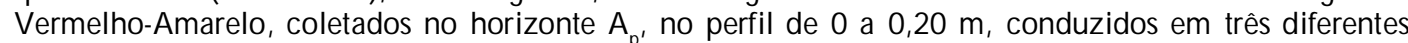
densidades $\left(1,3 ; 1,5\right.$ e $\left.1,7 \mathrm{~kg} \mathrm{dm}^{-3}\right)$ e três repetições. A cultura utilizada no experimento foi o milho (Zea mays), cultivar Itapuã 700. As variáveis avaliadas foram biomassa seca da parte aérea do milho (MS) e os teores de $\mathrm{N}, \mathrm{P}, \mathrm{K}, \mathrm{Ca}, \mathrm{Mg}$ e carbono orgânico total (COT) do solo. O s resultados obtidos indicaram que a aplicação do composto orgânico causou efeito significativo sobre os teores dos macronutrientes disponíveis e COT e a compactação do solo pouco afetou as variáveis estudadas.
\end{abstract}

Palavras-chave: aproveitamento de resíduos, adubação, densidade do solo, Zea mays

\section{Effect of compaction and organic compost application on corn biomass and macronutrient contents in soil}

\begin{abstract}
When well utilized, organic residues lead to great benefits making organic matter and nutrients available in soils. In this context, the present study had the objective to evaluate the effect of organic compost doses on two soils submitted to different compactions and on corn biomass. Thus, in 54 pots were added three doses 0,40 or $80 \mathrm{~g} \mathrm{dm}^{-3}$ of organic compost in a Dark Red Argisoil or Red Yellowish Argisoil, collected from the Ap horizon (depth of 0 to $0.20 \mathrm{~m}$ ), submitted to three compaction degrees $(1.3,1.5$ and $1.7 \mathrm{~kg}$ $\mathrm{dm}^{-3}$ ), with three replications. The crop used in the experiment was corn (Zea mays), cultivar Itapuã 700. The plant growth, and content of $\mathrm{N}, \mathrm{P}, \mathrm{K}, \mathrm{Ca}, \mathrm{Mg}$ and organic carbon (TOC) in soil were evaluated. The results point out that the organic compost application significantly affected soil $O C$ and macronutrients, but little effect was induced by the soil compaction on these variables.
\end{abstract}

Key word: residue use, fertilization, soil density, Zea mays

\footnotetext{
${ }^{1}$ Escola Agrotécnica de Iguatu, Rodovia Iguatu Várzea Alegre, km 5, Vila Cajazeiras, Iguatu-CE, CEP 63500-000

2 U FRPE. Rua Dom Manoel de Medeiros s/n, Dois Irmãos, Recife, PE, CEP 52171 - 900. Fone (81) 3320-6276. E-mail: rolim@dtr.ufrpe.br, egidio@dq.ufrpe.br, elvira.pedrosa@dtr.ufrpe.br, verofat@dtr.ufrpe.br

3 UFC, Campus do Pici: Bloco 804, CEP 60450-760. Fone 3366 9754, rntcosta@ufc.br
} 


\section{INTRODUÇÃO}

Nas centrais de abastecimento a comercialização de produtos agrícolas resulta em um resíduo de natureza orgânica oriundo das perdas e do processamento primário dos alimentos. Após a compostagem os resíduos são transformados em substâncias húmicas relativamente estáveis, composto orgânico que permite um aproveitamento melhor na adubação dos solos. Os compostos orgânicos se constituem, atualmente, em alternativa viável na substituição total ou parcial dos fertilizantes minerais. Os resíduos orgânicos, embora apresentem menores concentrações em nutrientes que os fertilizantes minerais possuem, em sua constituição, maior diversidade de elementos os quais, quando ausentes no solo, limitam a produção vegetal.

O uso agrícola de resíduos tem sido recomendado em virtude de proporcionar benefícios agronômicos, como elevação do pH do solo (Silva et al., 2001), redução da acidez potencial e aumento na disponibilidade de macronutrientes (Vieira \& Cardoso, 2003), além de representar um benefício de ordem social, devido à disposição final menos impactante no ambiente. Diversos trabalhos têm mostrado aumento na produção de matéria seca e grãos por espécies de interesse agronômico cultivadas em solos tratados com lodo de esgoto (Oliveira et al., 2009). Em alguns casos, o aumento é equiparável ou superior aos obtidos com a adubação mineral recomendada para as culturas (Da Ros et al., 1993).

Giffoni (1987), por sua vez, estudando o efeito de quatro fontes de matéria orgânica (esterco bovino, esterco de galinha, esterco de caprino e bagaço de carnaúba) sobre as propriedades físicas e químicas de um solo Aluvial Vértico halomórfico, concluiu que o esterco de galinha aumentou significativamente o P disponível enquanto os demais estercos praticamente mantiveram o nível de nutrientes do solo original. O K disponível aumentou em todas as fontes, destacando-se os estercos de caprino e de frango.

Entre os fatores que contribuem para o incremento da produtividade das culturas a disponibilidade de $\mathrm{N}$ é um dos mais importantes, pois se trata de um nutriente absorvido em maiores quantidades pela maioria das culturas (Marin et al., 2007). Em geral, os lodos de esgoto são ricos em N, significando que possuem alto potencial para serem utilizados como fertilizantes nitrogenados; este $\mathrm{N}$ está presente em várias formas orgânicas e inorgânicas mas nem todas são disponíveis para a nutrição da planta (Vieira \& Cardoso, 2003). Apesar disto, o manejo da adubação nitrogenada se torna difícil por ser o nitrogênio um elemento que apresenta dinâmica complexa e em virtude da adubação química não apresentar efeito residual (Raij, 1991); no entanto, a principal reserva de $\mathrm{N}$ no solo é a matéria orgânica, com grande significado para o suprimento do nutriente para as culturas.

Por outro lado, as plantas necessitam de condições físicas e químicas adequadas para realizar seu potencial produtivo, a compactação reduz o crescimento e aumenta as perdas de $\mathrm{N}$ por desnitrificação (Soane \& Ouwerkerk, 1994). Através da prática da adubação orgânica pode-se diminuir este efeito negativo com a vantagem, além da melhoria de algumas cacacterísticas físicas do solo, de promover o enriquecimento de macronutrientes para as culturas e aumentar a atividade microbiana do solo.

A resposta das principais plantas cultivadas à compactação ainda não é completamente conhecida. Dependendo da sensibilidade das espécies e das condições ambientais, tem-se observado reduções de até $75 \%$ da produtividade, como no feijoeiro quando submetido à compactação (Orzolek, 1991); entretanto, Oussible et al. (1992) encontraram efeitos menos drásticos no trigo cultivado em um solo franco-argiloso compactado a uma densidade de aproximadamente $1,51 \mathrm{~kg} \mathrm{dm}^{-3}$, em que verificaram reduções na produtividade de grãos e na matéria seca, de 9-20 e 12-23\%, respectivamente.

O presente estudo teve por objetivo verificar o efeito da aplicação de doses crescentes de composto orgânico em dois solos submetidos a diferentes compactações, cultivados com a cultura do milho.

\section{Material e mÉTodos}

O experimento foi realizado em casa de vegetação do Centro de Ciências Agrárias da Universidade Federal do Ceará, Campus do Pici.

Os solos utilizados no experimento apresentaram duas classes texturais: Argissolo Vermelho-Escuro (AVE) com textura franco arenosa e Argissolo Vermelho-Amarelo (AVA) com textura arenosa, provenientes do Município de Iguatu, CE, coletados no horizonte $A_{p}$, num perfil de 0 a $0,20 \mathrm{~m}$. A caracterização física e química dos solos estudados (Tabela 1) foi efetuada no Laboratório de Solos da UFC, segundo metodologia EMBRAPA (1997).

Tabela 1. Caracterização física e química dos solos utilizados no experimento

\begin{tabular}{|c|c|c|}
\hline Determinação & AVE & AVA \\
\hline Areia grossa $\left(\mathrm{g} \mathrm{kg}^{-1}\right)$ & 410 & 440 \\
\hline Areia fina $\left(\mathrm{g} \mathrm{kg}^{-1}\right)$ & 250 & 450 \\
\hline Silte $\left(\mathrm{g} \mathrm{kg}^{-1}\right)$ & 160 & 90 \\
\hline Argila $\left(\mathrm{g} \mathrm{kg}^{-1}\right)$ & 180 & 20 \\
\hline Densidade do solo $\left(\mathrm{kg} \mathrm{dm}^{-3}\right)$ & 1,42 & 1,48 \\
\hline Densidade de partículas $\left(\mathrm{kg} \mathrm{dm}^{-3}\right)$ & 2,68 & 2,73 \\
\hline Umidade na CC $\left({\left.\mathrm{g} 100 \mathrm{~g}^{-1}\right)^{*}}^{*}\right.$ & 10,37 & 2,51 \\
\hline 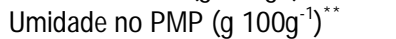 & 7,03 & 1,64 \\
\hline Classificação textural & Franco arenosa & Areia \\
\hline Nitrogênio - N ( $\left.\mathrm{g} \mathrm{kg}^{-1}\right)$ & 0,32 & 0,29 \\
\hline Fósforo - P (mg dm³) & 7 & 55 \\
\hline Potássio - $\mathrm{K}^{+}\left(\mathrm{mg} \mathrm{dm}^{-3}\right)$ & 189 & 23 \\
\hline Cálcio - $\mathrm{Ca}^{2+}\left(\mathrm{cmol}_{\mathrm{c}} \mathrm{dm}^{-3}\right)$ & 2,5 & 1,9 \\
\hline Magnésio - $\mathrm{Mg}^{2+}\left(\mathrm{cmol}_{\mathrm{c}} \mathrm{dm}^{-3}\right)$ & 2,2 & 1,7 \\
\hline Carbono orgânico total $\left(\mathrm{g} \mathrm{kg}^{-1}\right)$ & 2,89 & 2,69 \\
\hline Matéria orgânica $\left(\mathrm{g} \mathrm{kg}^{-1}\right)$ & 4,98 & 4,63 \\
\hline CE na pasta saturada $\left(\mathrm{dS} \mathrm{m}^{-1}\right)^{* * *}$ & 0,74 & 1,44 \\
\hline pH em água $(1: 2,5)$ & 7,2 & 6,5 \\
\hline
\end{tabular}

O composto orgânico utilizado foi produzido na Usina de Compostagem de Resíduos da Central de Abastecimento (CEASA, PE), cuja composição química determinada foi: nitrogênio, fósforo, potássio, cálcio, magnésio, umidade e 
matéria orgânica iguais a 0,$70 ; 0,43 ; 0,86 ; 19,92 ; 1,48 ; 14,23$ e $13,83 \%$, respectivamente. O nitrogênio foi determinado pelo método de Kjeldahl, fósforo por colorimetria do molibdovanadato, potássio por fotometria de chama, cálcio e magnésio por espectrofotometria de absorção atômica, umidade por evaporação e matéria orgânica por calcinação, todos de acordo com EMBRAPA (1997).

A cultura utilizada no experimento foi o milho (Zea mays L.), cultivar Itapuã 700, descrita como de ciclo curto, 100 dias, possuindo resistência moderada a doenças e boa resistência à seca, além de boa adaptabilidade a solos de baixa fertilidade.

O experimento foi conduzido em 54 vasos de PVC de $0,10 \mathrm{x}$ $0,30 \mathrm{~m}$ (diâmetro $\times$ altura, respectivamente). Os solos, após a coleta, foram secados ao ar, destorroados e passados em peneira de $4,76 \mathrm{~mm}$, pesados e adicionados a aproximadamente $10 \% \mathrm{de}$ água em peso, para facilitar o processo de compactação, a qual foi feita com a colocação de uma massa de solo previamente calculada, no vaso de PVC, em três camadas semelhantes, aplicando-se golpes de malho de madeira sobre o solo de cada camada, até a altura desejada, de modo que o conjunto atingisse as densidades D1=1,3; D2=1,5 e D3=1,7 $\mathrm{kg} \mathrm{dm}^{-3}$. Depois de preparados com solo nas diversas densidades, os vasos foram lentamente saturados através de fluxo de água vertical ascendente, com a finalidade de se evitar caminhos preferenciais da água e também das raízes; em seguida, foram levados à casa de vegetação e adicionado o composto orgânico nas doses estabelecidas 0 (testemunha); 40 (Dose 2) e 80 (Dose 3) $\mathrm{g} \mathrm{dm}^{-3}$ ), equivalentes a $0 ; 80$ e $160 \mathrm{tha}^{-1}$, base úmida.

Após três dias fez-se a semeadura empregando-se cinco sementes de milho e, oito dias depois, realizou-se o desbaste, deixando-se apenas duas plantas por vaso, as quais foram irrigadas diariamente com o mesmo volume de água, até o término do experimento, tendo-se o cuidado de não ultrapassar a capacidade de pote. $O$ cultivo foi conduzido durante 25 dias, tendo em vista o espaço reduzido do vaso, ocasião em que foi realizada a colheita da parte aérea das plantas, com corte do caule rente ao solo. Os materiais foram acondicionados em sacos de papel devidamente identificados e levados ao laboratório para determinação da quantidade de biomassa seca da parte aérea (MS).

O N total do solo foi determinado pelo método de Kjeldahl. O P disponível foi extraído com Mellich 1 e determinado por colorimetria; para os cátions trocáveis $\left(\mathrm{K}^{+}, \mathrm{Ca}^{2+} \mathrm{e} \mathrm{Mg}^{2+}\right)$ utilizouse o acetato de amônio $1 \mathrm{~N} \mathrm{pH} \mathrm{7,0,} \mathrm{determinando-se} \mathrm{o} \mathrm{Ca} \mathrm{e} \mathrm{o}$ $\mathrm{Mg}$ por titulação com EDTA $0,025 \mathrm{~N}$ e o K por fotometria de chama; o carbono orgânico total (COT) foi determinado por oxidação da matéria orgânica do solo com a solução de dicromato de potássio $0,4 \mathrm{~N}$; todas as determinações foram procedidas segundo a metodologia da EMBRAPA (1997).

Os tratamentos foram distribuídos em delineamento inteiramente casualizado, configurando-se em arranjo fatorial $2 \times 3 \times 3$, sendo dois solos (AVE e AVA), três valores de densidade (D1, D2 e D3) e três doses de composto orgânico, com três repetições, sendo realizadas a análise de variância e a comparação de médias pelo teste de Tukey, a nível de 5\% de probabilidade.

\section{RESULTADOS E DISCUSSÃO}

A análise de variância mostrou efeito significativo para o acúmulo de matéria seca em resposta à adubação com matéria orgânica e, para a interação da adubação com a densidade (Figura 1); no entanto, não houve efeito significativo em resposta ao tipo de solo. Considerando o efeito isolado, a adubação com a dose de $40 \mathrm{~g} \mathrm{dm}^{-3}$ de composto orgânico proporcionou acréscimo de mais de $100 \%$ na MS da parte aérea do milho, quando comparado como das plantas do tratamento testemunha porém não diferiu significativamente da dose de $80 \mathrm{~g} \mathrm{dm}^{-3}$.

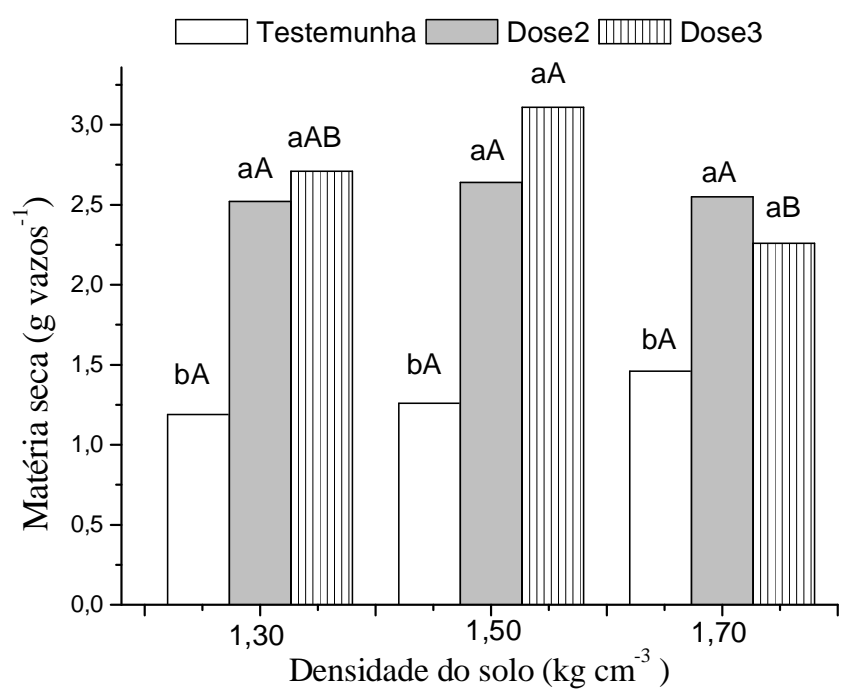

Obs.: Médias seguidas da mesma letra minúsculas para adubação e maiúsculas para compactação não diferem estatisticamente $(P \leq 0,05)$ pelo teste de Tukey

Figura 1. Acúmulo de matéria seca (M S) da parte aérea do milho e adubação com composto orgânico em função do grau de compactação do solo

A ausência do efeito da compactação do solo sobre o acúmulo de biomassa pelo milho sugere que a compactação não interfere na absorção dos nutrientes minerais pelas raízes das plantas, tal como mencionado por Beutler \& Centurion (2004) em relação às culturas do arroz e da soja.

Para o mesmo grau de compactação do solo houve efeito significativo da adubação sobre o teor de nitrogênio no solo, mais pronunciado no solo AVE (Figura 3A), cuja resposta indica que o solo franco-arenoso tem maior capacidade em reter matéria orgânica que o solo arenoso.

Isolando-se o efeito da adubação nota-se que a compactação mostrou efeito significativo sobre o teor de nitrogênio apenas no solo AVA (Figura 4A); contudo, o teor de nitrogênio foi mais elevado no solo AVE que no AVA.

O nitrogênio total inclui as formas orgânicas, que são as predominantes, e inorgâncias do elemento no solo. Embora esta característica nem sempre se relacione com a disponibilidade de nitrogênio, a relação com o teor de matéria orgânica do solo é sempre estreita (Raij, 1991). O composto orgânico utilizado continha cerca de $0,70 \%$ de $\mathrm{N}$ total; assim, serviu como fonte de reserva, sendo o teor de nitrogênio total influenciado positivamente com a adubação aplicada. 
Os teores de nitrogênio total obtidos nas plantas nos tratamentos que receberam adubação orgânica foram aproximadamente 111 e $152 \%$ superiores quando comparados com os do tratamento testemunha, nos solos AVE e AVA, respecticamente. $\mathrm{O}$ maior teor de $\mathrm{N}$ total nos tratamentos que receberam as dosagens evidencia o efeito residual do composto orgânico aplicado, corroborando com Stockdale et al. (2002), em que o uso de materiais orgânicos aumenta o $\mathrm{N}$ total do solo.

Com relação aos teores de fósforo residual no solo, a adubação orgânica influenciou significativamente a variável, em ambos os solos, porém mais acentuadamente no AVE do que no AVA (Figura 2A). Após o cultivo o solo AVE apresentou 283 e $523 \mathrm{dg} \mathrm{dm}^{3}$ de fósforo, respectivamente para as doses de 40 e $80 \mathrm{~g} \mathrm{dm}^{3}$ do composto orgânico enquanto o solo AVA apresentou 152 e $214 \mathrm{mg} \mathrm{dm}^{-3}$ de fósforo, respectivamente para as doses de 40 e $80 \mathrm{~g} \mathrm{dm}^{3}$. Esta resposta é coerente com a obtida para o teor de nitrogênio total no solo, confirmando a maior capacidade do solo franco-arenoso em armazenar matéria orgânica e nutriente, que o solo arenoso. Por outro lado, somente a dose de $40 \mathrm{~g} \mathrm{dm}^{3}$ de matéria orgânica foi suficiente para elevar o teor de fósforo no solo a um patamar de excelência. No Brasil, 90\% dos solos mostram teores de $\mathrm{P}$ disponíveis menores que $10 \mathrm{mg} \mathrm{dm}^{-3}$, nível considerado baixo (UFC, 1993).

Como previsto, o cultivo das plantas de milho proporcionou redução no teor de fósforo no solo, referente às parcelas no tratamento testemunha. Resultados semelhantes também foram observados por Matowo et al. (1999) em função da aplicação de fertilizantes nitrogenados em áreas sob sistema de plantio direto. Por outro lado, Gibson (1992), testando efeito de composto orgânico em Latossolo Amarelo, destacou que a dose de $10 \mathrm{t} \mathrm{ha}^{-1}$ elevou o teor de $\mathrm{P}$ do solo de 5 para $32 \mathrm{mg} \mathrm{dm}^{-3}$ $(540 \%)$.

O teor de potássio disponível nos solos após o cultivo do milho diferiu significativamente $(\mathrm{P} \leq 0,05)$ em função do tipo de solo e das doses do composto orgânico aplicado (Figura 2B). $\mathrm{Na}$ ausência da adubação ocorreu redução significativa no teor de potássio no solo, de 189 para $85 \mathrm{mg} \mathrm{dm}^{3}$ no solo AVE e de 23 para $12 \mathrm{mg} \mathrm{dm}^{3}$ para oAVA, fato explicado com a absorção desse nutriente pelas plantas. Por outro lado, a adubação aplicada foi suficiente para elevar o teor de potássio residual no solo para 210 e $380 \mathrm{mg} \mathrm{dm}^{3}$ respectivamente para as doses de 40 e 80 no solo AVE e para 150 e $240 \mathrm{mg} \mathrm{dm}^{3}$ no solo AVA; mais uma vez, o solo franco-arenoso (AVE) mostrou melhor capacidade de reter matéria orgânica e armazenar nutrientes que o solo arenoso (AVA). Nos dois tipos de solo, a dose de 40 $\mathrm{g} \mathrm{dm}^{3}$ do composto orgânico foi suficiente para elevar o teor do potássio no solo a um valor de boa fertilidade.

A análise de variância $(\mathrm{P} \leq 0,05)$ aplicada ao Ca (Figura $2 \mathrm{C}$ ) foi significativa para o fator solo, dose e para a interação solo $\mathrm{x}$ dose; no caso do solo, os maiores valores foram obtidos para o AVE seguido do AVA.

A aplicação do composto orgânico contribuiu para o aumento nos teores de Ca no solo, sendo os maiores valores obtidos com a aplicação da Dose 3, seguida da Dose 2 e todas superiores à testemunha. Especificamente no solo AVA, os maiores valores obtidos foram para a Dose 3 seguida da Dose 2 , iguais entre si, e ambas superiores à testemunha. A elevação do nível de Ca trocável dos solos após o cultivo nos diversos
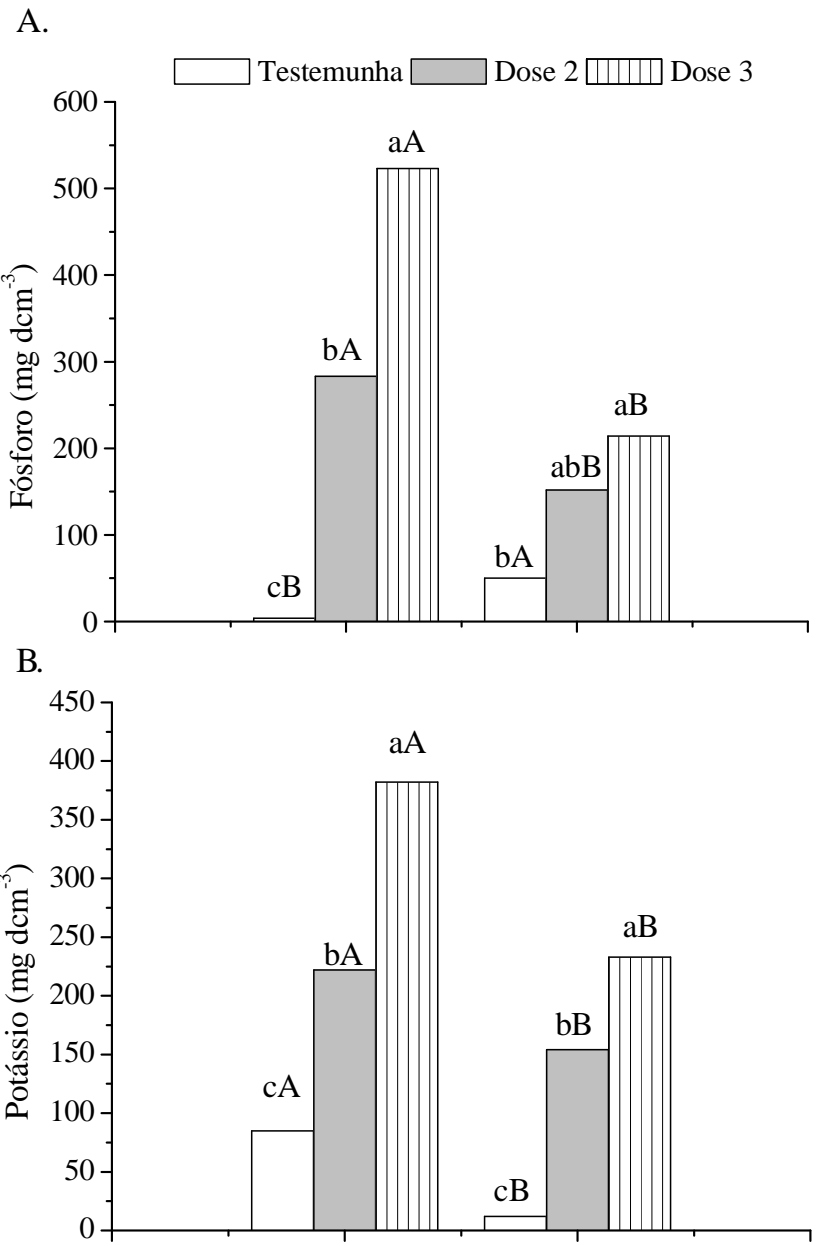

C.

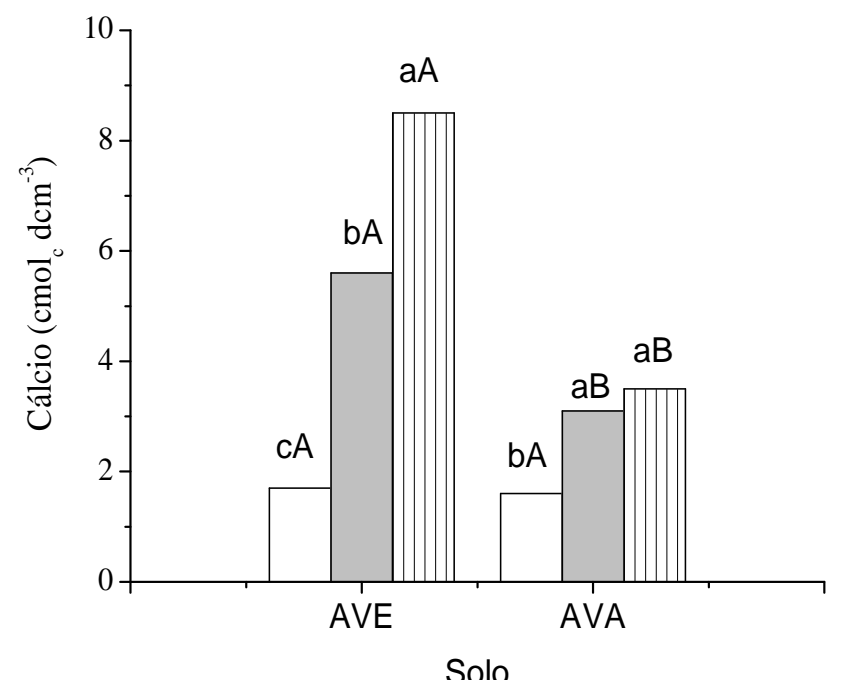

Obs.: Médias seguidas da mesma letra minúscula para adubação e maiúscula para solo, não diferem estatisticamente $(P \leq 0,05)$ pelo teste de Tukey; AVE - Argissolo Vermelho-Escuro; AVA - Argissolo Vermelho-Amarelo

Figura 2. Teores de $P(A), K(B)$ e $C a(C)$ no solo, em função da dose do composto orgânico

tratamentos é explicada pelo alto nível deste elemento no composto $(19,92 \%)$, comprovado também pelo aumento da presença desse nutriente na matéria seca da parte aérea do milho (Rodrigues et al., 2009). Os resultados corroboram com os encontrados quando da aplicação sistemática de esterco, 
compostos orgânicos e incorporação de culturas de cobertura, observando-se maior aporte de Ca (Mader et al., 2002).

Constatou-se pequena redução no teor de magnésio de ambos os solos, após o cultivo, nas parcelas não adubadas; contudo, isolando-se o efeito da compactação a aplicação do composto orgânico na dose de $40 \mathrm{~g} \mathrm{dm}^{3}$ elevou o teor de magnésio para $2,74 \mathrm{cmol}_{\mathrm{c}} \mathrm{dm}^{-3}$ no solo AVE, valor este que não diferiu significativamente do valor obtido com a aplicação da dose de $80 \mathrm{~g} \mathrm{dm}^{3}$ do composto (Figura 3B). Mader et al. (2002), também encontraram aumento significativo no teor de magnésio

A.

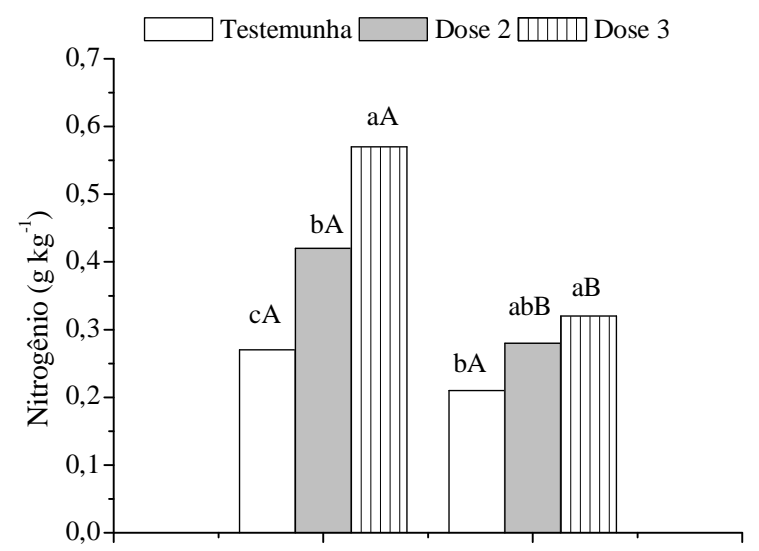

B.

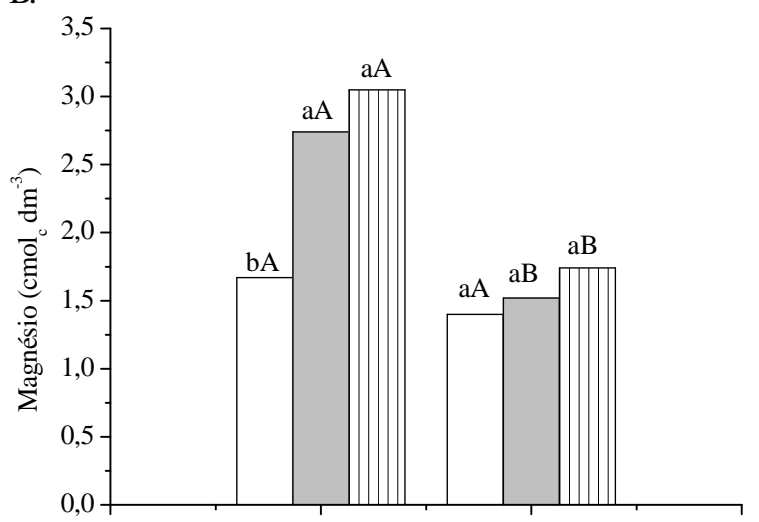

C.

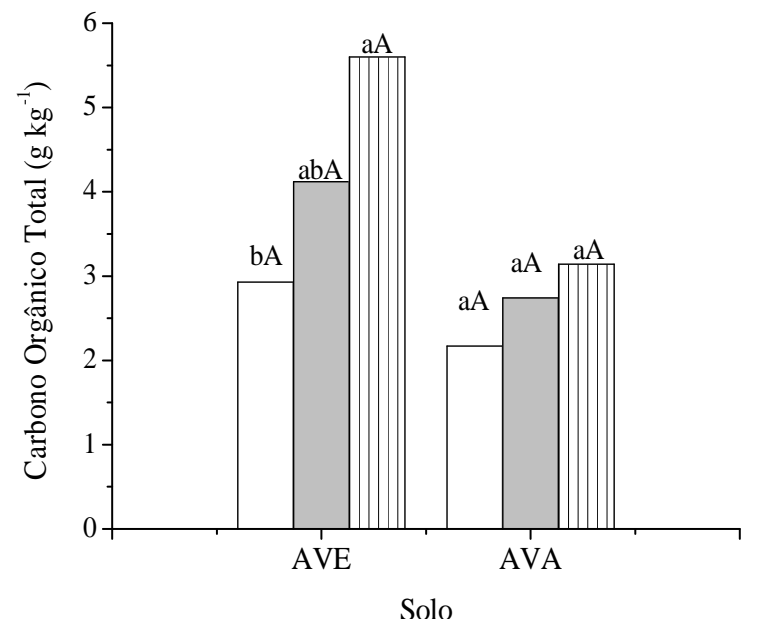

Obs.: Médias seguidas da mesma letra minúscula para adubação e maiúscula para solo, não diferem estatisticamente $(P \leq 0,05)$ pelo teste de Tukey; AVE - Argissolo Vermelho-Escuro; AVA - Argissolo Vermelho-Amarelo

Figura 3. Teores de N (A), Mg (B) e COT (C) no solo em função da dose do composto orgânico no solo em função da aplicação de composto orgânico; no solo AVA não houve diferença significativa entre os teores de magnésio residual para nenhuma das doses do composto.

Isolando-se o efeito da adubação, a compactação do solo AVE elevou sua densidade para $1,5 \mathrm{~kg} \mathrm{dm}^{3}$ sem causar efeito significativo sobre o teor de magnésio residual do solo; mas, com a densidade de $1,7 \mathrm{~kg} \mathrm{dm}^{3}$, ocorreu decréscimo no teor de magnésio residual do solo (Figura 4B); por outro lado, o solo AVA não mostrou resposta significativa para o teor de magnésio residual do solo, em função do grau de compactação do solo.

A.

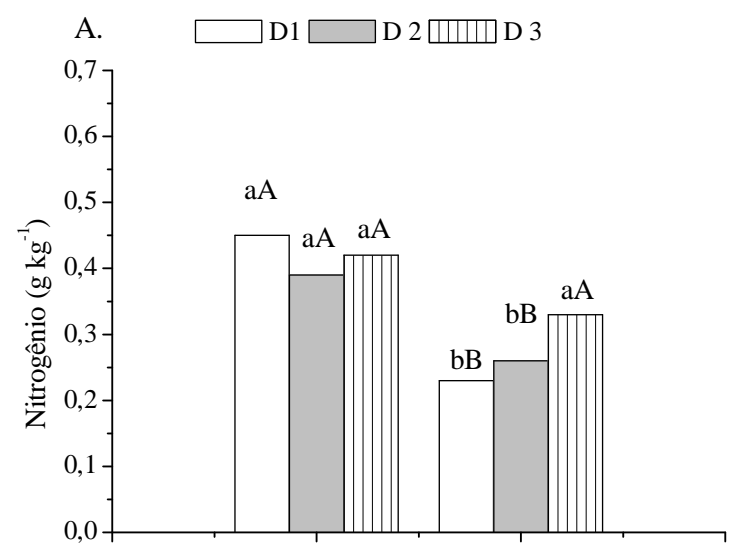

B.

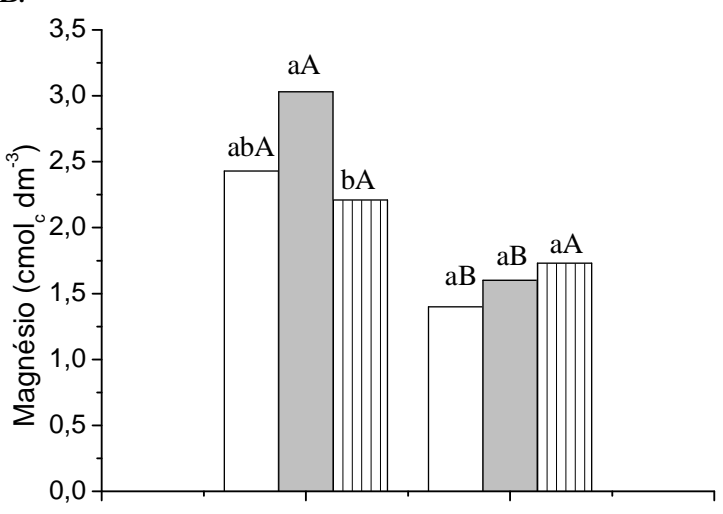

C.

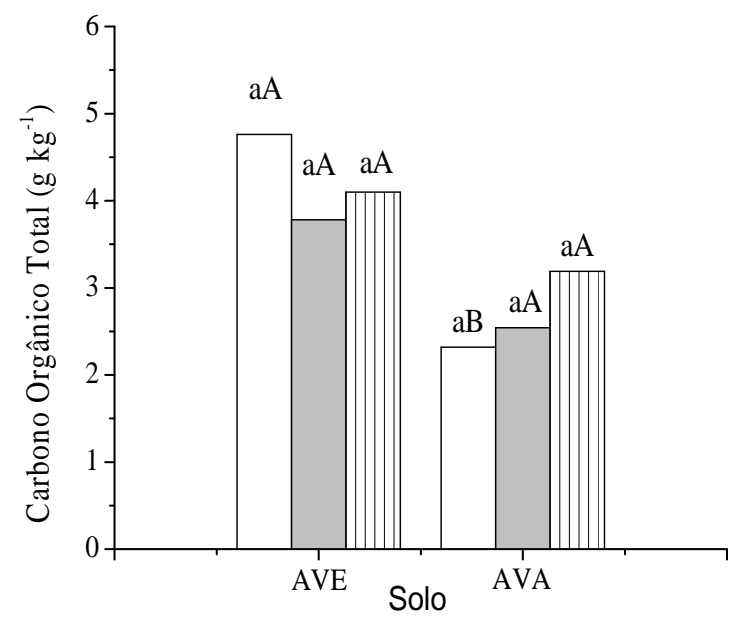

Obs.: Médias seguidas da mesma letra minúscula para adubação e maiúscula para solo, não diferem estatisticamente $(P \leq 0,05)$ pelo teste de Tukey; AVE - Argissolo Vermelho-Escuro; AVA - Argissolo Vermelho-Amarelo

Figura 4. Teores de N (A), Mg (B) e CO T (C) no solo em função da compactação do solo 
Isolando-se o efeito da compactação do solo tem-se que o teor de carbono orgânico total (COT) no solo AVE após o cultivo, aumentou com a adubação de $80 \mathrm{~g} \mathrm{dm}^{3}$ do composto orgânico enquanto a dose de $40 \mathrm{~g} \mathrm{dm}^{3}$ não diferiu significativamente do tratamento testemunha (Figura 3C). Não houve efeito significativo da adubação sobre o teor de COT no solo AVA. Giffoni (1987) trabalhou com quatro fontes de matéria orgânica e observou aumento nos teores de COT do solo para as quatro fontes estudadas.

A compactação do solo não afetou significativamente o teor de COT no solo AVE nem no solo AVA (Figura 4C); entretanto, os teores de COT foram significativamente superiores aos do solo AVE, em relação ao solo AVA, ambos submetidos à compactação equivalente à densidade de $1,3 \mathrm{~kg} \mathrm{dm}^{3}$. Quando esses os solos foram submetidos à compactação equivalente à densidade de 1,5 ou $1,7 \mathrm{~kg} \mathrm{dm}^{3}$, não houve diferença significativa entre os tipos de solo, no que se refere ao teor de COT.

\section{Conclusões}

1. As dosagens aplicadas do composto orgânico proporcionaram efeitos significativos no crescimento do milho, em termos de biomassa seca;

2. A dose de $40 \mathrm{~g}$ do composto por $\mathrm{kg}$ de solo foi suficiente para melhorar a fertilidade do solo franco-arenoso;

3. O solo franco-arenoso (AVE) apresentou melhores respostas que o solo arenoso (AVA) no que se refere à capacidade de armazenar nutrientes minerais.

4. O lodo de esgoto aumentou a fertilidade do solo pela elevação dos teores de matéria orgânica, incrementando o crescimento e a produção de matéria seca do milho.

5. A compactação do solo pouco influenciou as variáveis estudadas.

\section{LITERATURA CITADA}

Beutler, A. N.; Centurion, J. F. Compactação do solo no desenvolvimento radicular e na produtividade de soja. Pesquisa Agropecuária Brasileira, v.39, p.581-8, 2004.

Da Ros, C. O.; Aita, C.; Ceretta, C. A.; Fries, M. R. Lodo de esgoto: efeito imediato no milheto e residual na associação aveia-ervilhaca. Revista Brasileira de Ciência do Solo, v.17, p.257-261, 1993.

Defelipo, B. V.; Nogueira, A. V.; Loudes, E. G.; Alvarez, Z. V. H. Eficiência agronômica do lodo de esgoto proveniente de uma siderúrgica. Revista Brasileira de Ciência do Solo, v.15, p.389-393, 1991.

EMBRAPA - Empresa Brasileira de Pesquisa Agropecuária. Manual de métodos de análise de solos. 2 ed. Rio de Janeiro: EMBRAPA, 1997. 212p.
Gibson, C. P. Efeito do composto no Latossolo Amarelo: Produtividade e alterações químicas. Belém: FCAP, 1992. 99p. Dissertação Mestrado

Giffoni, V. L. R. Efeito de resíduos orgânicos no cultivo do arroz e nas propriedades físicas e químicas do solo Aluvial Vértico sódico. Fortaleza: UFC, 1987. 65p. Dissertação Mestrado

Mader, P.; Fliessbach, A.; Dubois, D.; Gunst, L.; Fried, P. Niggli, U. Soil fertility and biodiversity in organic farming. Science, v.296, p.1694-1697, 2002.

Marin, A. M. P.; Menezes, R. S. C.; Salcedo, I. H. Produtividade de milho solteiro ou em aléias de gliricídia adubado com duas fontes orgânicas. Pesquisa Agropecuária Brasileira, v.42, p.669-677, 2007.

Matowo, P. R.; Pierzynski, G. M.; Whitney, D.; Lamond, R. E. Soil chemical properties as influenced by tillage and nitrogen source, placement, and rates after 10 years of continuous sorghum. Soil \& Tillage Research, v.50, p.11-19, 1999.

Medeiros, D. M.; Soares, A. A.; Guimarães, R. M. Compactação do solo e manejo da água. I: efeitos sobre a absorção de N, $\mathrm{P}, \mathrm{K}$, massa seca de raízes e parte aérea de plantas de arroz. Ciências Agrotécnicas, v.29, p.940-947, 2005

Oliveira, J. P. B.; Lopes, J. C.; Alexandre, R. S.; Jasper, A. P.; Santos, L. N. S. Efeito do lodo de esgoto no desenvolvimento inicial de duas cultivares de mamona em dois tipos de solos. Engenharia Ambiental, v.5, p. 203-219, 2009.

Orzolek, M. D. Establishment of vegetables in the field. Hort Technology, v.1, p.78-81, 1991.

Oussible, M.; Crookston, R. K.; Larson, W. E. Subsurfase compactation reduces the root and shoot growth and grain yield of wheat. Agronomy Journal, v.84, p.34-38, 1992.

Rodrigues, P. N. F.; Rolim, M. M.; Bezerra Neto, E.; Pedrosa, E. M.; Oliveira, V. S. Crescimento e composição mineral do milho em função da compactação do solo e da aplicação de composto orgânico. Revista Brasileira de Engenharia Agrícola e Ambiental, v.13, p.94-99, 2009.

Silva, F. C.; Boaretto, A. E.; Berton, R. S.; Zotellih, B.; Pexe, C. A.; Bernardes, E. M. Efeito na fertilidade de um Argissolo Vermelho-Amarelo cultivado com cana de açúcar. Pesquisa Agropecuária Brasileira, v.36, p.831-840. 2001.

Soane, B. D.; Ouwerkerk, C. V. Soil compactation in crop production. Amsterdam: Elsevier, 1994. 660p.

Stockdale, E. A.; Shepherd, M. A.; Fortune, S; Cuttle, S. P. Soil fertility in organic farming systems - Fundamentally different? Soil Use and Management, v.18, p.301-308, 2002.

UFC - Universidade Federal do Ceará. Recomendações de adubações e calagem para o estado do Ceará. Fortaleza, UFC/CCA/Departamento de Ciências do Solo, 1993. 247p.

van Raij, B. Fertilidade do solo e adubação. Piracicaba: Ceres, Potafos, 1991, 343p.

Vieira, R. F.; Cardoso, A. A. Variações nos teores de nitrogênio mineral em solo suplementado com lodo de esgoto. Pesquisa Agropecuária Brasileira, v.38, p.867- 874, 2003. 